\title{
The Research for Flexible Product Family Manufacturing Based on Real Options
}

\author{
Maozhu Jin, Xiangguo Tian \\ Business School, Sichuan University (China) \\ jinmaozbu@scu.edu.cn,35921141@.qq.com
}

Received: November 2014

Accepted: February 2015

\section{Abstract:}

Purpose: The goal of this paper is to find the best production strategy for product portfolio, which means the largest value of the options. And finally, give a case and find the solution of the optimal production strategy for product portfolio.

Design/methodology/approach: This article, based on the production with characteristics of a call option and 0-1 integer programming model, build new-product portfolio strategy, and through case demonstrate that traditional method underestimates the value of the product portfolio.

Finding: According to market being volatility and uncertainty and the production can being delayed, firms can flexibly arrange the best time for products to manufacture. Use real options theory to analyze product decision and the best production timing decision. Find the total options value is higher than the traditional methods.

Research limitations/implications: We are not applied to real option pricing theory in modular flexible production system. We just applied real option pricing theory to the product platform. The basic model need to improve. While the thinking of this paper provides some research ideas for flexible production systems based on real option in further research. 
Practical Implications: The introduction of the real option make the company can achieve dynamic planning and flexible management for production of product portfolio and get the better benefit.

Originality/value: The central contribution of this paper is to introduce the option mechanism in the production timing for the product portfolio.

Keywords: flexible product platform, product family, real option, binary pricing theory, 0-1 mathematical programming

\section{Introduction}

Now Design for Mass Customization (DFMC) has become the national scholars and business research focus. Product family developed based product platform is one effective way to achieve mass customization. The introduction of flexible product platform can further enhance the product platform configuration, adapting to market demand diversity and variability. Build modular product family based on flexible product platform, and according to market demand characteristics, the modules are divided into universal modules and adjusted variable flexible modules. These will not only adapt to the market's diversity and solve the economy for the mass production, but also adapt to market developments variability and ensure the stability of product platforms. Weck, Suh and Chang (2004) were to study optimal product platform number for enterprise in light of identifying market segments, and make its total product family profit maximization on the basis. Wei, Liu and Yang (2006) researched the product configuration design knowledge, variant design and organization and management methods of their process knowledge. Particularly, the product configuration design and variant design provides some ideas for this article. Shi, Jiang, Yan and Tan (2009) from a qualitative point of view put forward product family based on flexible product platform, while it is not given the flexible product platform development guidelines from a quantitative point of view and made the best product portfolio strategy according to customer demand. However, its ideas for module division are worth learning.

\section{Theoretical Background}

\subsection{Real Options Overview}

Stewart Myers, the professor of MIT in 1977, proposed the concept of real options. Real options theory derived from financial options theory, which meant applying the financial options theory to physical assets. The basic characteristics of real option are the asymmetry 
for owner of the rights and obligations. Namely the investors with the real options of investment projects have the right to choose to implement the project when environmental is benefit, and have no obligation to implement the project in the poor environment. Real option theory in the attitude towards uncertainty is better than the traditional evaluation methods (e.g. DCF, NPV) for capital investment project. So many researchers are willing to introduce option theory into the evaluation of investment projects in order to improve the scientific for the project investment decision. Trigeorgis (1996) systematically expounded real options and built a theoretical framework of real options; Real option pricing methods-binary tree method was helpful for this paper. Tao and Neufville (2004) built option physical system by using discrete mixed integer programming options, which played a guiding role in this article. Zhang and Xia (2009) gave a review about the option pricing theory and point out the major field of the application of real option. Xia and Xilin (2006) used binary option pricing methods and integer programming to research multi-enterprise project portfolio decision, and the main idea of this article is from this literature. Peng and Zheng (2006) studied under conditions of uncertainty investment decision with real options method and it proposed threshold value of investments which is referential significance to this article. Anderson and Weersink (2014) study show that net revenues is higher by using the real options approach compared to the NPV approach. Bengtsson and Olhager (2002) studied flexibility of product portfolio for a number of related products under internal resource constraints. Meng and Shengce (2009) applied the real options approach to assess product planning for mass customization, and established real option value evaluation model for product planning.

\subsection{The Application of Real Options in Flexible Product Portfolio}

Many literature about the real options mainly focused on technology investment, R \& D risk projects and the flexible assessment for these issues, while there is a few about the product options and product production decisions. Banerjee and Weck (2004) discussed the frame of the product options, options flexible assessment and flexible policy, but they did not elaborate real options how to apply in the product optimized decision. Ford and Sobek (2005) adapts real options concepts to product development management. McIntyre and Chintakananda (2013) proposed that value of product release from a real options perspective. These ideas are formalized in a conceptual framework and a series of research propositions, and implications for theory and practice at the intersection of network effects and real options are offered. While this paper researched optimal product portfolio in flexible production system based on binary real option pricing method and flexible product platform. The product in each segment can be seen as a European call option in the paper, and the product portfolio can be seen as a several European call option portfolio problems. On the basis, this paper, considering the enterprise resource constraints and using 0-1 integer programming to pursue the option value 
maximization for product portfolio, study the optimal product portfolio selection and its best production of timing.

\subsection{Modularity for Flexible Product Platform}

Flexible product platform can be defined as an organization or system consisting of common elements and variant elements (e.g. components, processes or interfaces). When the common elements was fixed, through adding special elements and dynamically adjusting the values of the flexible element according to customer demand, firms can get a series of product variants and product family. During the process of flexible product platform design, according to Quality Function Deployment method, these elements can be modularized (Fujita, 2002). Then flexible product platform can be designed as a series of common modules and dynamically adjustable flexible modules. Meanwhile, during the process of the module design, dynamically adjust the main attributes parameters for flexible modules, which can meet different market segments and ensure the stability of the product platform (Magnusson \& Pasche, 2014). In the modularity for flexible product platform, different modules had relatively independent function. The module combination had no functional redundancy; meanwhile it had flexibility and adaptability.

\section{Product Portfolio Research Based on Real Options}

When firm produced product portfolio, if the marginal contribution of one of the products is positive, firm can selected the product, and if the contribution margin is negative, the firm temporarily did not assembled or produced the product. This selection process depended on the demand in the market segments and manufacturing costs. Therefore, this option can be seen as a call option. When the product marginal contribution is positive, the firm exercised the right, namely manufactured or assembled the product. This paper assumed that a production system is a series of European call option, and two options in different periods are mutually independent. So, the goal was to pursue a finite number of call options to possibly produce the greatest contribution margin. This article will use the binomial option pricing methods and 0-1 mathematical programming to study the optimal product portfolio in the resource limitations.

\subsection{Building of Real Option Model}

Suppose that the firm for product families currently owns $N$ product and these products, and the $N$ products are independent of each other. For the product $j(j=1,2, \ldots, N)$, its production 
time can be decomposed into $T$ phases. In each phase, the market demand is $D_{j}$. According to option binary pricing theory, let relative proportions of market demand growth or decline be $u_{j}$ and $d_{j}$ respectively, and there is $u_{j}>1>d_{j}>0$. By risk-neutral assumption, the risk-neutral probability can be expressed as $p_{j}=\frac{1+r-d_{j}}{u_{j}-d_{j}}$, where $r$ is risk-free rate.

In the enterprise product family, assume that the initial demand for the product $j$ is $D_{j, 0}$. Formula (1) gives the demand $D_{j}$ possible values for the product $j$ in the $T$ phase. Thus, $D_{j}$ has $(T+1)(T+2) / 2$ kind possible values in the $T$ phase. And assume $D_{j, S_{i}(t)}$ represents the product $j$ possible demand state for the stage $t(t=0,1,2, \ldots, T)$, and there is $1 \leq \mathrm{I} \leq \mathrm{t}+1$. In the state $S_{i}(t)$ the expected demand $D_{j, s_{i}(t)}$ equation for product $j$ can be expressed as:

$$
D_{j, S_{i}(t)}=u_{j}^{t-(i-1)} \times d_{j}^{i-1} \times D_{j, 0}
$$

Can be assembled products for enterprise is similar to "Option" for financial call option. Namely firms have the right to assemble the product but not the obligation at some time in the future. When firms decide to assemble the product, the firms exercise the options, and give up waiting to obtain the market new information affecting on spending will or timing. Once the market conditions are reversed, firms cannot stop the action. So the lost option value is an opportunity cost. $F\left(D_{j}, S_{i}(t)\right)$ representatives option value in the state $S_{i}(t)$. Let the decision variable $x_{j}=1$ or 0 , and respectively the firms will choose or not choose to assembly product $j$. Resource constraint model $M_{1}$ can be established in order to choose the product portfolio. Variables hypothesis are shown below.

$I_{j}$-Fixed costs for assembling the product $j$;

$P_{j}$-Price for product $j$;

$V_{c_{j k}}-$ Unit cost of common module $k$ for product $j ; k=1,2, \ldots, n$;

$V_{F_{j q}}-$ Unit cost of flexible module $q$ for product $j ; q=1,2, \ldots, m$;

$Y_{j k}-$ Require the number modules of common module $k$ for product $j$, and is integer;

$Q_{j q}$-Require the number modules of flexible module $q$ for product $j$, and is integer;

$C E_{\max }^{k}-$ The largest supply of common module $k$;

$F E_{\max }^{q}-$ The largest supply of flexible module $q$;

$F\left(D_{j}, S_{i}(t)\right)$-the option value for product $j$ in the state $S_{i}(t)$. 
The product portfolio select model $M_{1}$ :

$$
\begin{gathered}
\operatorname{Max} \sum_{j=1}^{N} F\left(D_{j}, S_{i}(0)\right) x_{j} \\
\text { S.T. } \quad \sum_{j=1}^{N} x_{j} Y_{j k} D_{j, S_{1}(0)} \leq C E_{\max }^{k}, k=1,2, \cdots, n \\
\sum_{j=1}^{N} x_{j} Q_{j q} D_{, S_{1}(0)} \leq C E_{\max }^{q}, q=1,2, \cdots, m \\
x_{j}=0 \text { or } 1, j=1,2, \cdots, N
\end{gathered}
$$

Objective function for the model $M_{1}$ means to option value of selected a range of product portfolio under the enterprise resource constraints. Based on binary option pricing theory, $F\left(D_{j}, S_{i}(t)\right)$ can be obtained through a recursive $F\left(D_{j}, S_{i}(0)\right)$ from back to front. Where is

$$
\begin{gathered}
F\left(D_{j}, S_{i}(T)\right)=\operatorname{Max}\left[\left(P_{j}-\sum_{k=1}^{n} Y_{j k} V_{C_{1 k}}-\sum_{q=1}^{m} Q_{j q} V_{F_{1 q}}\right) D_{j, S_{i}(T)}-I_{j}, 0\right] \\
F\left(D_{j}, S_{i}(t)\right)=\operatorname{Max}\left[\frac{p_{j} F\left(D_{j}, S_{i}(t+1)\right)+\left(1-p_{j}\right) F\left(D_{j}, S_{i+1}(t+1)\right)}{1+r}, 0\right]
\end{gathered}
$$

\subsection{Optimization of Production Decisions for Product Portfolio}

According to the model, the firm can select the most valuable products to form product portfolio from the product family. Since the selection of products assembly time is flexible for the firm, the firm can further optimize product portfolio production decisions, to achieve maximum production value for the product portfolio. Finally, based on the model $M_{1}$ building the optimal production timing for product portfolio is necessary. Next, establish the production timing decision model $M_{2}$ for product portfolio.

Depending on the market demand conditions for the products, the firm for the stage $T$ has $2^{T}$ kinds of strategies to choose from. Assume, $A_{k}$ represents the $k$ strategy, and when the firm selects strategy $A_{k}$ to produce, the corresponding option value for the product $j$ can be expressed by $F\left(D_{j \prime} A_{k}(0)\right)$. There is

When

$$
t=0, F\left(D_{j}, A_{k}(0)\right)=F\left(D_{j}, S_{1}(0)\right), 1 \leq K \leq 2^{T}
$$


When

$$
t=1, \quad F\left(D_{j}, A_{k}(1)\right)=\left\{\begin{array}{l}
F\left(D_{j}, S_{1}(1)\right), 1 \leq K \leq 2^{T-1} \\
F\left(D_{j}, S_{2}(1)\right), 2^{T-1}+1 \leq K \leq 2^{T}
\end{array}\right.
$$

When

$$
t=2, F\left(D_{j}, A_{k}(2)\right)=\left\{\begin{array}{l}
F\left(D_{j}, S_{1}(2)\right), 1 \leq K \leq 2^{T-2} \\
F\left(D_{j}, S_{2}(2)\right), 2^{T-2}+1 \leq K \leq 2^{T-2}+2^{T-1} \\
F\left(D_{j}, S_{3}(2)\right), 2^{T-2}+2^{T-1}+1 \leq K \leq 2^{T}
\end{array}\right.
$$

When

$$
t=T, F\left(D_{j}, A_{k}(T)\right)=\left\{\begin{array}{l}
F\left(D_{j}, S_{1}(T)\right), K=1 \\
F\left(D_{j}, S_{2}(T)\right), 2 \leq K \leq T+1 \\
\cdots \\
F\left(D_{j}, S_{T}(T)\right), 2^{T}-T \leq K \leq 2^{T}-1 \\
F\left(D_{j}, S_{T+1}(T)\right), K=2^{T}
\end{array}\right.
$$

Take decision variable $Z_{j, A_{k}(t)}$, and $D_{j}^{*}$ expresses the critical value of the market demand for product $j$ through real option method, where is $Z_{j, A_{k}(t)}=0$ or 1 . When $D_{j, A_{k}(t)} \leq D_{j}^{*}$, there is $Z_{j, A_{k}(t)}=0$; When $D_{j, A_{k}(t)} \geq D_{j}^{*}$, there is $Z_{j, A_{k}(t)}=0$ or 1 , and because the actual demand exceeds the critical value, the product is not to be produced under internal resource constraints. So, the best production timing decision model $M_{2}$ for product portfolio is following:

$$
\operatorname{Max} \sum_{j=1}^{N} \sum_{t=0}^{T} \sum_{k=1}^{2^{T}} F\left(D_{j}, A_{k}(t)\right) Z_{j, A_{k}(t)}
$$

s.t.

$$
\begin{gathered}
\sum_{t=0}^{T} \sum_{j=1}^{N} D_{j, S_{i}(t)} Y_{j k} Z_{j, A_{k}(t)} \leq C E_{\max }^{k}, k=1,2, \cdots, n, 1 \leq K \leq 2^{T} \\
\sum_{t=0}^{T} \sum_{j=1}^{N} D_{j, S_{i}(t)} Q_{j q} Z_{j, A_{k}(t)} \leq F E_{\max }^{q}, q=1,2, \cdots, m, 1 \leq K \leq 2^{T} \\
Z_{j, A_{k}(t)}\left(D_{j}^{*}-D_{j, S_{i}(t)}\right) \leq 0, j=1,2, \cdots, N, 1 \leq K \leq 2^{T} \\
\sum_{t=0}^{T} Z_{j, A_{k}(t)} \leq 1 ; t=0,1, \cdots, N \\
Z_{j, A_{k}(t)}=0 \mathrm{or} 1 ; j=1,2, \cdots, N, 1 \leq K \leq 2^{T}
\end{gathered}
$$




\section{The Application of the Models}

One of the product families in the firm includes three products, and the current market demand, sales prices, fixed costs for production and relevant parameters for binomial model are shown in Table 1.

Based on modular product platform, every product consists of a series of modules, and Table 2 shows the internal module structure for the product 1, 2, 3. Furthermore, because the resources are scarce, the enterprise only meet customer limited demand within the scope of their production capacity. Supplying the maximum number of modules and variable cost of each module can be seen from Table 2.

Assuming the probability of expected demand fluctuations for three products is $50 \%$. According to Tables 1 and 2, three products can generate gross profit, respectively: 100,100, 153,750 , and 99,320 . Due to resource constraints, the firm will immediately produce a product with a larger gross profit: product 2 and 1 , and the sum of gross portfolio is 253,850 .

\begin{tabular}{|c|c|c|c|c|c|c|}
\hline Product Number & $\boldsymbol{\mu}_{\boldsymbol{j}}$ & $\boldsymbol{\sigma}_{\boldsymbol{j}}$ & $\boldsymbol{I}_{\boldsymbol{j}}$ & $\boldsymbol{D}_{\boldsymbol{j}, \boldsymbol{0}}$ & $\boldsymbol{D}_{\boldsymbol{j}}{ }^{*}$ & $\boldsymbol{P}_{\boldsymbol{j}}$ \\
\hline 1 & 0.015 & 0.065 & 170 & 12 & 12.73 & 126.5 \\
\hline 2 & 0.005 & 0.075 & 150 & 13 & 12.17 & 114 \\
\hline 3 & 0.019 & 0.060 & 160 & 11 & 12.22 & 117 \\
\hline
\end{tabular}

Table 1. Binary model parameter values in $(r=5 \%) D_{j, A_{k}(t)} \geq D_{j}^{*}$

\begin{tabular}{|c|c|c|c|c|c|c|c|c|c|}
\hline \multirow{2}{*}{\multicolumn{2}{|c|}{ Modules }} & \multicolumn{4}{|c|}{ Common modules } & \multicolumn{4}{|c|}{ Flexible modules } \\
\hline & & $C E^{1}$ & $C E^{2}$ & $C E^{3}$ & $C E^{4}$ & $F E^{1}$ & $F E^{2}$ & $F E^{3}$ & $F E^{4}$ \\
\hline \multirow{3}{*}{ Products } & 1 & 1 & 2 & 1 & 2 & 0 & 2 & 2 & 1 \\
\hline & 2 & 1 & 1 & 2 & 1 & 1 & 2 & 1 & 0 \\
\hline & 3 & 2 & 1 & 1 & 1 & 2 & 1 & 0 & 2 \\
\hline \multicolumn{2}{|c|}{ Limit amount of modules } & 45 & 40 & 45 & 45 & 33 & 55 & 35 & 30 \\
\hline \multicolumn{2}{|c|}{ Module variable costs } & 10 & 10 & 10 & 10 & 10 & 10 & 10 & 10 \\
\hline
\end{tabular}

Table 2. Internal module structure, limit amount and costs for product 1, 2, 3

Use real options theory to analyze product decision. Calculate the relevant parameters $u_{j}=e^{\sigma \sqrt{\Delta t}}$ and $d_{j}=1 / u_{j}$, and on the basis calculate the risk-neutral probability $p_{j}$. 


\begin{tabular}{|c|c|c|c|c|c|}
\hline \multicolumn{2}{|c|}{ Products } & $\boldsymbol{t}=\mathbf{0}$ & $\boldsymbol{t}=\mathbf{1}$ & $\boldsymbol{t}=\mathbf{2}$ & $\boldsymbol{t}=\mathbf{3}$ \\
\hline \multirow{3}{*}{$i=1$} & 1 & 12.00 & 12.80 & 13.66 & 14.58 \\
\cline { 2 - 6 } & 2 & 13.00 & 14.01 & 15.11 & 16.29 \\
\cline { 2 - 6 } & 3 & 11.00 & 11.68 & 12.41 & 13.18 \\
\hline \multirow{3}{*}{$i=2$} & & & 11.24 & 12.00 & 12.80 \\
\cline { 2 - 6 } & & & 12.06 & 13.00 & 14.01 \\
\hline \multirow{3}{*}{$i=3$} & & & 10.36 & 11.00 & 11.68 \\
\cline { 2 - 6 } & & & & 10.54 & 11.24 \\
\hline \multirow{3}{*}{$i=4$} & & & & 11.20 & 12.06 \\
\cline { 2 - 6 } & & & & 9.76 & 10.36 \\
\hline & & & & & \\
\hline
\end{tabular}

Table 3. The Expected Demand for Products

According to (1), obtain the expected demand for products in various stages, as shown in Table 3. By (5) and (6), obtain value of the options for products under the expected demand, as shown in Table 4.

\begin{tabular}{|c|c|c|c|c|c|}
\hline \multicolumn{2}{|c|}{ Products } & $\boldsymbol{t}=\mathbf{0}$ & $\boldsymbol{t}=\mathbf{1}$ & $\boldsymbol{t}=\mathbf{2}$ & $\boldsymbol{t}=\mathbf{3}$ \\
\hline \multirow{3}{*}{$i=1$} & 1 & 51.16 & 57.09 & 63.55 & 70.57 \\
\cline { 2 - 6 } & 2 & 52.40 & 60.12 & 68.66 & 78.06 \\
\cline { 2 - 6 } & 3 & 48.81 & 53.51 & 58.58 & 64.06 \\
\hline \multirow{3}{*}{$i=2$} & & & 31.41 & 36.03 & 41.20 \\
\cline { 2 - 6 } & & & 32.86 & 39.08 & 46.14 \\
\hline \multirow{3}{*}{$i=3$} & & & 30.96 & 34.59 & 38.56 \\
\cline { 2 - 6 } & & & & 12.79 & 15.46 \\
\hline \multirow{3}{*}{$i=4$} & & & & 14.59 & 18.84 \\
\cline { 2 - 6 } & & & & 13.82 & 16.12 \\
\hline & & & & & 0 \\
\hline
\end{tabular}

Table 4. Option Value for Products 


\begin{tabular}{|c|c|c|c|c|}
\hline Products & $\boldsymbol{t}=\mathbf{0}$ & $\boldsymbol{t}=\mathbf{1}$ & $\boldsymbol{t}=\mathbf{2}$ & $\boldsymbol{t}=\mathbf{3}$ \\
\hline 1 & 0 & 1 & 0 & 0 \\
\hline 2 & 1 & 1 & 1 & 1 \\
\hline 3 & 0 & 0 & 0 & 0 \\
\hline & & 0 & 0 & 0 \\
\hline & & 1 & 0 & 1 \\
\hline & & 0 & 0 & 0 \\
\hline & & & 0 & 1 \\
\hline & & & 0 & 0 \\
\hline & & & & 0 \\
\hline & & & & 0 \\
\hline
\end{tabular}

Note: In Table 5, " 1 "represents can immediately produce, and " 0 " means continue to wait

Table 5. The Optimal Strategy for Product portfolio

Production method decision for the product portfolio based on real option is that the gross products are equivalent to the option value, and choose the larger value of options for products to produce. By the mode $M_{1}$, companies will choose product 2 and 1 to produce under resource constraints. Due to a product in the market demand 120,000 less than the product of the critical value 127,300 , the firm will not immediately produce product 1 . From Table 2 , product 1 starts to manufacture at the stage $t=1$ and product 2 can be manufacture at any stage. While for product 3 the production time is later and the option value is smaller. Through model $M_{1}$, the product portfolio are product 1 and product 2 .

On the basis of the select product portfolio, apply model and obtain the production timing for the product portfolio. As production costs are one-time payments and internal resource are constrained, each product can assemble only once. By the data in Table 1, 2, 3, and 5, run $M_{2}$ through Lingo software and get optimal production strategies of product portfolio. The results are shown in Table 6. Finally, the firm should immediately assemble product 2 and assemble product 1 at the stage $t=1$. The total options value is $1,094,900$, and, compared with the traditional methods, it is higher than 840,850 . 


\begin{tabular}{|c|c|c|c|c|}
\hline Products & $\boldsymbol{t}=\mathbf{0}$ & $\boldsymbol{t}=\mathbf{1}$ & $\boldsymbol{t}=\mathbf{2}$ & $\boldsymbol{t}=\mathbf{3}$ \\
\hline 1 & 0 & 1 & 0 & 0 \\
\hline 2 & 1 & 0 & 0 & 0 \\
\hline & & 0 & 1 & 0 \\
\hline & & 0 & 0 & 1 \\
\hline & & & 0 & 0 \\
\hline & & & 0 & 0 \\
\hline & & & & 0 \\
\hline
\end{tabular}

Note: In Table 6, " 1 " represents can immediately produce, and " 0 " means continue to wait

Table 6. Production Timing for the Optimal Strategy

\section{Concluding Remarks}

According to the production can being delayed, multi-product portfolio is like a series of financial call options. According to market volatility and uncertainty, firms can flexibly arrange the best time for products to manufacture. This article, based on the production with characteristics of a call option and 0-1 integer programming model, build new-product portfolio strategy, and through case demonstrate that traditional method underestimates the value of the product portfolio. Since the model introduces the option mechanism, which allows companies can achieve dynamic planning and flexible management for production of product portfolio. And the thinking of this paper provides some research ideas for flexible production systems based on real option in further research. In the future real option pricing theory can be applied to modular flexible production system, where each module is given to options in the product platform. Combining game theory, find the optimal product platform strategy and meet customer needs.

\section{Acknowledgment}

The authors wish to thank the Major International Joint Research Program of the National Natural Science Foundation of China (Grant No. 71020107027), the National Natural Science Foundation of China (Grant No. 71001075) and Humanities and Social Sciences project of The Ministry of education of China (Grant No.12YJC630023), Central University Fund of Sichuan University with No.skqy201112 under which the present work was possible. 


\section{References}

Anderson R.C., \& Weersink, A. (2014). A Real Options Approach for the Investment Decisions of a Farm-Based Anaerobic Digester[]]. Canadian Journal of Agricultural Economics/Revue canadienne d'agroeconomie, 62(1), 69-87. http://dx.doi.org/10.1111/cjag.12019

Banerjee, P., \& Weck, O.L. (2004). Flexibility strategy-valuing flexible product options. In INCOSE/ICSE conference on synergy between systems engineering and project management, Las Vegas, Nevada.

Bengtsson, J., \& Olhager, J. (2002). The impact of the product portfolio on the value of flexibility. The international Journal of Management Science, 30, 265-273.

Ford, D.N., \& Sobek, D.K. (2005). Adapting real options to new product development by modeling the second Toyota paradox[J]. Engineering Management, IEEE Transactions on, 52(2), 175-185. http://dx.doi.org/10.1109/TEM.2005.844466

Fujita, K. (2002). Product variety optimization under modular architecture. Computer-Aided Design, 34, 953-965. http://dx.doi.org/10.1016/S0010-4485(01)00149-X

Magnusson, M., \& Pasche, M. (2014). A Contingency-Based Approach to the Use of Product Platforms and Modules in New Product Development. J Prod Innov Manag, 31(3). http://dx.doi.org/10.1111/jpim.12106

McIntyre, D.P., \& Chintakananda, A. (2013). A real options approach to releasing "network" products. Journal of High Technology Management Research, 24(1), 42-52.

http://dx.doi.org/10.1016/j.hitech.2013.02.007

Meng, F., \& Shengce, H. (2009). One kind of product planning based on real options model. Machinery in Chinese, China, 46-48.

Peng, C., \& Zheng, F. (2006). Multi-project Investment Decision based on real options. Market Modernization, China, 271-272.

Shi, K., Jiang, P., Yan, H., \& Tan, R. (2009). Product family design based on flexible product platform. Computer Integrated Manufacturing Systems, China, 15, 1880-1889.

Tao, W., \& Neufville, R. (2004). Building Real Options into Physical Systems with Stochastic Mixed-Integer Programming. $8^{\text {Th }}$ Real Options Annual International Conferrence, June; Montreal, Canada.

Trigeorgis, L. (1996). Real options: Managerial flexibility and Strategy in Resource Allocation. The MIT Press, 215-237. 
Wei, X., Liu, X., \& Yang, C. (2006). Study on the Knowledge Management Methodologies for Mass Customization Design. Transactions of the Chinese Society for Agricultural Machinery, China, 37, 133-137.

Weck, O.L., Suh, E.S., \& Chang, D. (2004). Product Family Strategy and Platform Design Optimzation. MIT Working Paper, America.

Xia, F., \& Xilin, L. (2006). The Study of Multiple Projects Investment Decision Based on Real Option. Chinese Journal of Management Science, China, 14, 21-24.

Zhang, J., \& Xia, E. (2009). A reviewed: the real option pricing theory research. Productivity Research, China, 174-176.

Journal of Industrial Engineering and Management, 2015 (www.jiem.org)

Article's contents are provided on a Attribution-Non Commercial 3.0 Creative commons license. Readers are allowed to copy, distribute and communicate article's contents, provided the author's and Journal of Industrial Engineering and Management's names are included. It must not be used for commercial purposes. To see the complete license contents, please visit http://creativecommons.org/licenses/by-nc/3.0/. 